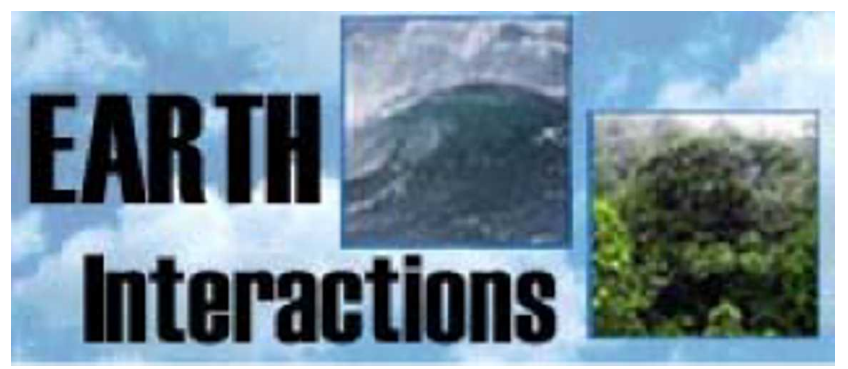

Copyright $\odot$ 2008, Paper 12-004; 5,931 words, 6 Figures, 0 Animations, 1 Table. http://EarthInteractions.org

\title{
Landslide Risk Analysis using a New Constitutive Relationship for Granular Flow
}

\section{Diandong Ren* and Lance M. Leslie}

School of Meteorology, University of Oklahoma, Norman, Oklahoma

\section{David Karoly}

School of Earth Sciences, University of Melbourne, Melbourne, Australia

Received 30 May 2007; accepted 6 December 2007

\begin{abstract}
In this study, landslide potential is investigated, using a new constitutive relationship for granular flow in a numerical model. Unique to this study is an original relationship between soil moisture and the inertial number for soil particles. This numerical model can be applied to arbitrary soil slab profile configurations and to the analysis of natural disasters, such as mudslides, glacier creeping, avalanches, landslips, and other pyroclastic flows. Here the focus is on mudslides.

The authors examine the effects of bed slope and soil slab thickness, soil layered profile configuration, soil moisture content, basal sliding, and the growth of vegetation, and show that increased soil moisture enhances instability primarily by decreasing soil strength, together with increasing loading. Moreover, clay soils generally require a smaller relative saturation than sandy soils for sliding to commence. For a stable configuration, such as a small slope and/or dry soil, the basal sliding is absorbed if the perturbation magnitude is
\end{abstract}

* Corresponding author address: Dr. Diandong Ren, School of Meteorology, University of Oklahoma, National Weather Center, 120 David L. Boren Blvd., Norman, OK 73072.

E-mail address: dd_ren@rossby.metr.ou.edu 
Earth Interactions - Volume 12 (2008) - Paper No. 4 - Page 2

small. However, large perturbations can trigger significant-scale mudslides by liquefying the soil slab.

The role of vegetation depends on the wet soil thickness and the spacing between vegetation roots. The thinner the saturated soil layer, the slower the flow, giving the vegetation additional time to extract soil moisture and slow down the flow. By analyzing the effect of the root system on the stress distribution, it is shown that closer tree spacing increases the drag effects on the velocity field, provided that the root system is deeper than the shearing zone.

Finally, the authors investigated a two-layer soil profile, namely, sand above clay. A significant stress jump occurs at the interface of the two media.

KEYWORDS: Landslide; Global warming; Granular flow rheology

\section{Introduction}

Mudslides and similar flows are major global natural hazards. At present they are receiving increasing research attention (see, e.g., Kalaugher et al. 2000; Tegzes et al. 2006; Huang and Garcia 1998). Most literature on granular flow has been limited to laboratory experiments or theoretical studies (Tegzes et al. 2006; Pouliquen and Forterre 2002; Huang and Garcia 1998; Mills et al. 1999; Daerr and Douady 1999). These and some field studies (e.g., reviewed in Qian and Wan 1986; Li et al. 1983) have focused primarily on mudslides moving down a long slope, and only limited research has included risk analysis. Here we develop a numerical model that describes both the flow fields and the stress distribution within a saturated soil resting on an arbitrary slope. By analyzing the stress distribution under vegetated and nonvegetated conditions for various vertical profiles of the saturated soil, we show that the model also can be used to investigate mudslide potential under a range of environments including warming climate conditions. The model has wide applications to glaciers, avalanches, coastal erosion, varying ocean levels, and lava flows.

The speed of a mudslide is the single most important factor that impacts people and structures, as it determines the spill coverage area and destructive capacity. In accessing the various factors influencing mudslide material behavior and the mechanisms of its generation-such as topography, basal sliding, the slope, bed roughness, soil moisture content, saturated layer thickness, and soil type vertical arrangement-we study their influence on the flow speeds for the unstable cases and stress distributions for the stable cases.

Our main objective is to gain insight into the physical basis for the triggering and enhancing of mudslide flows in terms of basal character, soil moisture, and vegetation. This study is a first step toward understanding human-induced influences on the hydrological cycle and their potential impacts on mudslide occurrence.

\section{Model for salturated soil resting on a slope}

Van der Veen and Whillans (Van der Veen and Whillans 1989) proposed a force-balance model for glacier flow. This model does not include the inertial 
terms and assumes a steady flow. Although, with the appropriate constitutive relationship for granular material instead of ice, it can be used to estimate the critical point at which flow commences, that is, the failure yield stress; it cannot be used to estimate the free surface shape after sliding has ceased or to estimate the flow speed of the mudslide and its spill range.

We propose a new model based on the incompressible Navier-Stokes formulation. The mass conservation equation is

$$
\boldsymbol{\nabla} \cdot \mathbf{V}=0
$$

and the momentum conservation equation is

$$
\rho\left[\frac{\partial \mathbf{V}}{\partial t}+\boldsymbol{\nabla} \cdot(\mathbf{V} \otimes \mathbf{V})\right]=\boldsymbol{\nabla} \cdot \boldsymbol{\sigma}+F,
$$

where $\rho$ is density, $\mathbf{V}$ is velocity vector, $\boldsymbol{\sigma}$ is internal stress tensor, and $F$ is the body force (e.g., gravity $\rho g$ ).

Instead of the standard decomposition of the internal tensor into static stress and dynamic stress parts, here we decompose it into a lithostatic $(L)$ and a resistive $(R)$ part (Van der Veen and Whillans 1989). Defining the lithostatic stress as the weight of wet soil above a level $z$, then

$$
L=-\rho g(h-z),
$$

where $h$ is the elevation of the free surface.

The full stress tensor $\sigma_{i j}$ is now written as

$$
\sigma_{i j}=R_{i j}+\delta_{i j} L
$$

where $R_{i j}$ denotes the components of the resistive tensor. Comparing this decomposition with the standard deviotoric decomposition (Frenette et al. 2002), we obtain the "new" constitutive relations in resistive stress terms:

$$
\begin{cases}R_{i j}=\nu \dot{\varepsilon}_{i j} & i \neq j=x, y, z \\ R_{i i}=\nu\left(2 \dot{\varepsilon}_{i j}+\dot{\varepsilon}_{i j}\right)+R_{Z Z} & i \neq j=x, y .\end{cases}
$$

In the numerical model, we introduce a $Z$-coordinate system transformation, defined by

$$
Z=\frac{h-z}{H}
$$

where $H(x, y)$ is the thickness of the saturated soil slab. After some mathematical manipulation, we obtain the three governing equations:

$$
\left\{\begin{array}{c}
\frac{\partial R_{x x}}{\partial x}+\frac{\Delta Z_{x}}{H} \frac{\partial R_{x x}}{\partial Z}+\frac{\partial R_{x y}}{\partial y}+\frac{\Delta Z_{y}}{H} \frac{\partial R_{x y}}{\partial Z}-\rho g \frac{\partial h}{\partial x}-\frac{1}{H} \frac{\partial R_{x z}}{\partial Z}=\rho \frac{d u}{d t} \\
\frac{\partial R_{x y}}{\partial x}+\frac{\Delta Z_{x}}{H} \frac{\partial R_{x y}}{\partial Z}+\frac{\partial R_{y y}}{\partial y}+\frac{\Delta Z_{y}}{H} \frac{\partial R_{y y}}{\partial Z}-\rho g \frac{\partial h}{\partial y}-\frac{1}{H} \frac{\partial R_{y z}}{\partial Z}=\rho \frac{d v}{d t} \\
\frac{\partial R_{x z}}{\partial x}+\frac{\Delta Z_{x}}{H} \frac{\partial R_{x z}}{\partial Z}+\frac{\partial R_{z y}}{\partial y}+\frac{\Delta Z_{y}}{H} \frac{\partial R_{z y}}{\partial Z}-0-\frac{1}{H} \frac{\partial R_{z z}}{\partial Z}=\rho \frac{d w}{d t}
\end{array}\right.
$$


Earth Interactions - Volume 12 (2008) - Paper No. 4 • Page 4

where $\Delta Z_{x}=[\partial h(x, y) / \partial x]-Z[\partial H(x, y) / \partial x]$ is the slope of the $Z$ surface in the $x$ direction; similarly, $\Delta Z_{y}$ is the slope of the $Z$ surface in the $y$ direction. Figure 1 is a schematic diagram of the computed field showing the variables and the coordinates.

Applying the constitutive relationship (see below) reduces the unknowns to the three velocity components $(u, v$, and $w)$. Note that at given time, in addition to satisfying the vertical motion equation, the vertical resistive stress $R_{z z}$ is obtained from boundary conditions (Jaeger 1969).

\subsection{A new constitutive relationship for granular flow}

Soil at near saturation acts like elasticoplastic material (Keen 1931; Baver 1940). Based on a study of steady flows on rough rigid inclined plane, a new constitutive relationship recently was proposed for granular flow (Jop et al. 2006):

$$
\nu=\left(\mu_{0}+\frac{\mu_{1}-\mu_{0}}{I_{0} / I+1}\right) \frac{S}{\left|\dot{\varepsilon}_{e}\right|},
$$

where $\nu$ is viscosity; $S=\left[R_{k k}-\rho g(h-z)\right] / 3$ is the isotropic (spherical) part of the stress tensor $\boldsymbol{\sigma} ; \mu_{0}$ and $\mu_{1}$ are the limiting values for friction coefficient $\mu$; $\left|\dot{\varepsilon}_{e}\right|$ is the effective strain rate and $\left|\dot{\varepsilon}_{e}\right|=\left(0.5 \dot{\varepsilon}_{i j} \cdot \dot{\varepsilon}_{i j}\right)^{0.5} ; I_{0}$ is a constant depending on the local slope of the footing bed as well as the material properties; and $I$ is

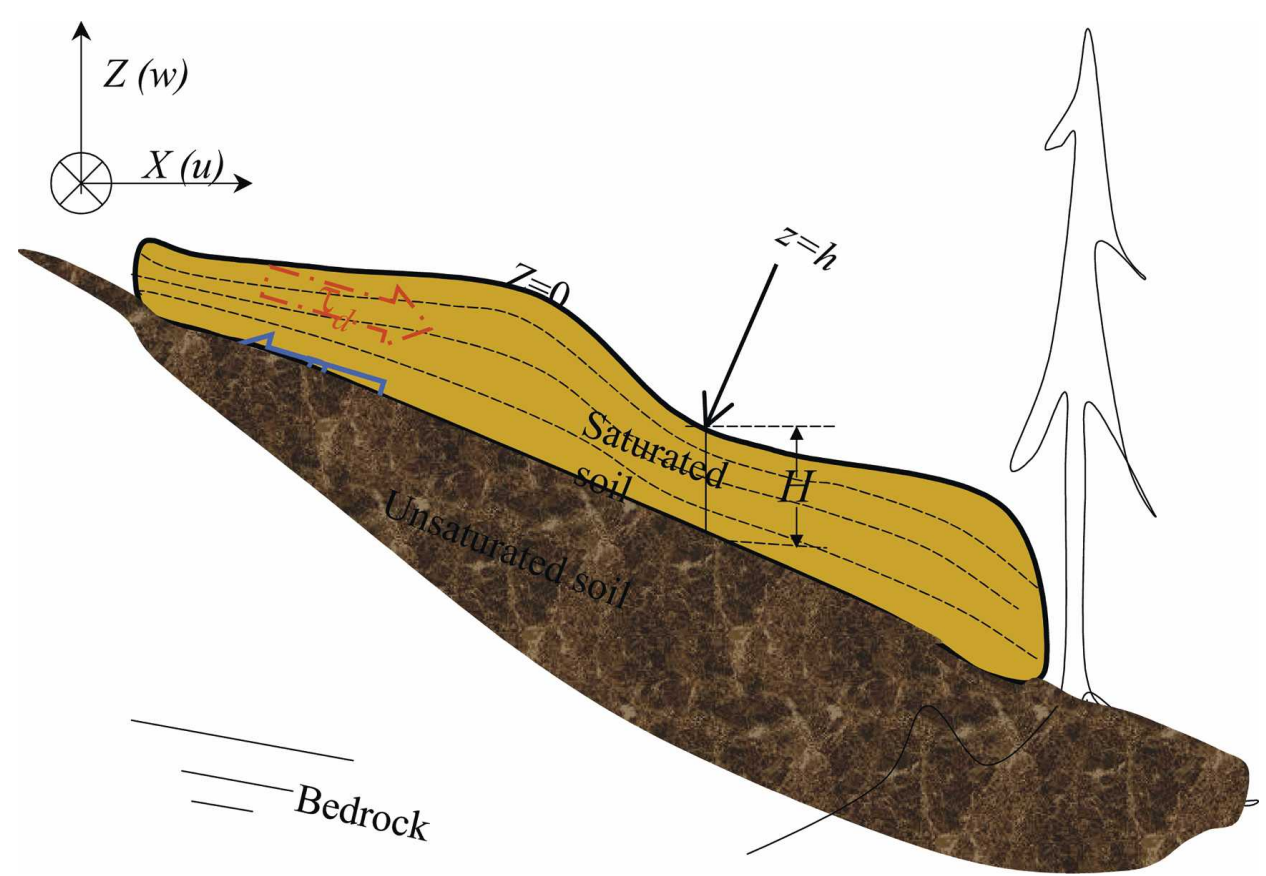

Figure 1. A simplified (2D) diagram of the 3D model used in this study, illustrating the coordinates, variables, and the computed field (the saturated soil). Note that the $Z$ coordinate is upright, not following the local slopes of the simulated domain. 
inertial number and is defined as $I=\left|\dot{\varepsilon}_{e}\right| d /\left(S / \rho_{s}\right)^{0.5}$, where $d$ is particle diameter $\left(7.5 \times 10^{-4} \mathrm{~m}\right.$ for sand and $1.5 \times 10^{-6} \mathrm{~m}$ for clay) and $\rho_{s}$ is soil particle density, estimated from soil bulk density and porosity. Assuming that the wet soil is incompressible, and postulating that the rheology of the mud is independent of the third invariant of the stress tensor, the stress-strain rate relationship is readily cast as Equation (5).

The rheology presented here admits the Drucker-Prager yield criterion (Drucker and Prager 1952; Frenette et al. 2002) and has the advantage of a continuous description of the passage of granular material from the moving (viscous) to the stationary (viscoplastic) state. However, it does not in general satisfy the MohrCoulomb failure criterion, because the cohesion is significant before soil moisture enters the funicular stage and then the capillary stage. For saturated clay soil or sandy soils, the cohesion is very small (Roscoe et al. 1958) and the MohrCoulomb failure criterion is satisfied. By adapting the new rheology (Jop et al. 2006), we can generalize the flow and solid states of the soil. That is, sliding commences when the driving force [the $\rho g \nabla h$ term on the left-hand side of Equation (7)] exceeds the shear strength of the soil.

For convenience, we define a diagnostic property, the bulk driving stress similar to $\tau_{d}$ defined in Van der Veen and Whillans (Van der Veen and Whillans 1989), which is the vertically averaged $\rho g \nabla h$ terms in Equation (7). Similarly, a bulk resistive stress $\tau_{b}$ is defined as the vertical average of all left-hand-side terms of Equation (7) other than the $\rho g \nabla h$ term.

\subsection{Consideration of soil moisture effects}

For soil under a normal soil moisture regime, cohesion, dilatation, and friction all affect shear strength. Our parameterization of the soil moisture effects is based primarily on the moisture cycle discussed in detail in Keen (Keen 1931, 115-121). Specifically, we follow Pouliquen and Forterre (Pouliquen and Forterre 2002) in setting up the parameters of $I_{0}$ for sandy and clay soils. The value of $\mu_{0}$ depends on the material and is roughly equal to the average angle of repose of the material. For dry soils, we take $\mu_{0}=1.1$ for sand and $\mu_{0}=0.3$ for clay; that is, $\Phi_{0}=$ $\arctan (1.1)$ for sand and $\Phi_{0}=\arctan (0.3)$ for saturated clay; $\mu_{0}$ also depends on the moisture (see, e.g., Tegzes et al. 2006; Iordanoff et al. 2005). For sandy soil, soil moisture content does not play a significant role in affecting $\mu_{0}$. For clay soils, we consider two effects: the increase of the effective radius of particle and the reduction of the $\mu_{0}$. The soil moisture impacts on effective particle size are parameterized as $d_{e}=d\left[1+1000\left(d_{\text {loam }} / d\right)^{3}\left(w-w_{\text {wilt }} / w_{\text {sat }}-w_{\text {wilt }}\right)\right]^{1 / 3}$, and take effect only for soil moisture above the wilting point and less than one-third of saturation. This covers roughly the pendular and earlier funicular stage (Keen 1931). The most prominent effect of soil moisture is its effect on $\mu_{0}$ (Iordanoff et al. 2005), primarily because we rely upon a linear yield strain relationship to determine the onset of motion. In this study, we simply multiply by a factor $\left[1+0.02\left(w-w_{\text {wilt }} / w_{\text {sat }}-w_{\text {wilt }}\right)\right]$ to implement this effect.

\section{Numerical experiments}

Throughout this study, mud is assumed to be produced only through soil moisture increments in the soil slab. Thus, the true steady state is the stationary state. 
Flow patterns are determined by viscosity and the external factors such as bed slope and saturated soil depth. Throughout, we assume two-dimensional (2D) topography: a $1500 \mathrm{~m} \times 1500 \mathrm{~m}$ square area of constant bedding plane slope angle $(\beta)$ of $22^{\circ}$, with a downslope gradient along the ground from points $(0,0)$ through $(1500,1500)$. The horizontal resolution is $50 \mathrm{~m} \times 50 \mathrm{~m}$ and vertically we use 11 layers to resolve the entire saturated soil slab. The time step is $0.001 \mathrm{~s}$ and we output the fields every 4 s (i.e., 4000 steps). The bottom surface is assumed to be no-slip. However, several lateral boundary conditions are available on option. The zero-stress conditions are applied for up- and downstream lateral boundaries except when otherwise explicitly stated, such as for the dynamic effects of vegetation.

We analyze a range of factors in triggering and enhancing mudslides, so it is necessary to specify a reference model run, hereafter denoted as CNTL. In the CNTL, we specify the soil properties according that of sand (see Table 1; cf. Kohnke 1968, p. 82). The soil moisture content is specified as 0.8 relative saturation $(\Theta)$. Uniform soil depths $H=H_{0}=1.1 \mathrm{~m}$ are used.

\section{Results and discussion}

For the reference run, CNTL, Figures $2 \mathrm{a}-\mathrm{c}$ show the velocity field cross sections along the vertical diagonal plane across slope top $(0,0)$ and toe $(1.5 \mathrm{~km}, 1.5 \mathrm{~km})$, at three times: 36,116 , and $228 \mathrm{~s}$. The velocity profile with depth has a maximum at the surface and decreases gradually to zero at the bottom. This is realistic (Jop et al. 2006; Bolt et al. 1975). The development of the flow field is shown in these three panels. Initially, there is rapid acceleration before the flow is fully developed, reaching a maximum surface layer speed of $2.24 \mathrm{~m} \mathrm{~s}^{-1}$. The magnitude of the downslope flow becomes almost uniform. With the thinning of the upstream mud, the flow there is decelerated gradually, whereas the flow downstream is nearly constant (keep a magnitude of $\sim 2.2 \mathrm{~m} \mathrm{~s}^{-1}$ ).

The dynamical change in soil thickness is simulated realistically (Figure 2d). The soil thickness starts shrinking upstream and propagates down at an accelerating rate initially and gradually reaches a steady rate. The thinning process is systematic because of the zero-stress lateral boundary setting, the uniform initial soil slab thickness, and the flat bed slope. The 2D views of the soil slab thickness indicate that the soil profile evolutions are steady and will eventually deplete the sand.

To assess the role of the soil thickness profile, we also test a nonuniform soil thickness profile confined by two bell-shaped surfaces mimicking, respectively, bedrock and surface topography. Using the $x$ direction as an example, in the case of uniform soil thickness the acceleration is caused by the inability of the vertical

Table 1. Independent soil properties used in this study (Kohnke 1968, p. 82).

\begin{tabular}{lcccccc}
\hline & $\begin{array}{c}\text { Particle } \\
\text { diameter } d(\mathrm{~m})\end{array}$ & $\begin{array}{c}\text { Dry bulk density } \\
\left(10^{3} \mathrm{~kg} \mathrm{~m}^{-3}\right)\end{array}$ & Porosity $\phi$ & $\begin{array}{c}\text { Repose } \\
\text { angle } \mu_{0}\end{array}$ & $\begin{array}{c}\text { Wilting } \\
\text { point } w_{\text {wilt }}\end{array}$ & $\begin{array}{c}\text { Saturation } \\
\text { point } w_{\text {sat }}\end{array}$ \\
\hline Sand & $7.5 \times 10^{-4}$ & 1.8 & 0.30 & 1.1 & 0.05 & 0.5 \\
Clay & $1.5 \times 10^{-6}$ & 2.4 & 0.20 & 0.3 & 0.12 & 0.6 \\
\hline
\end{tabular}



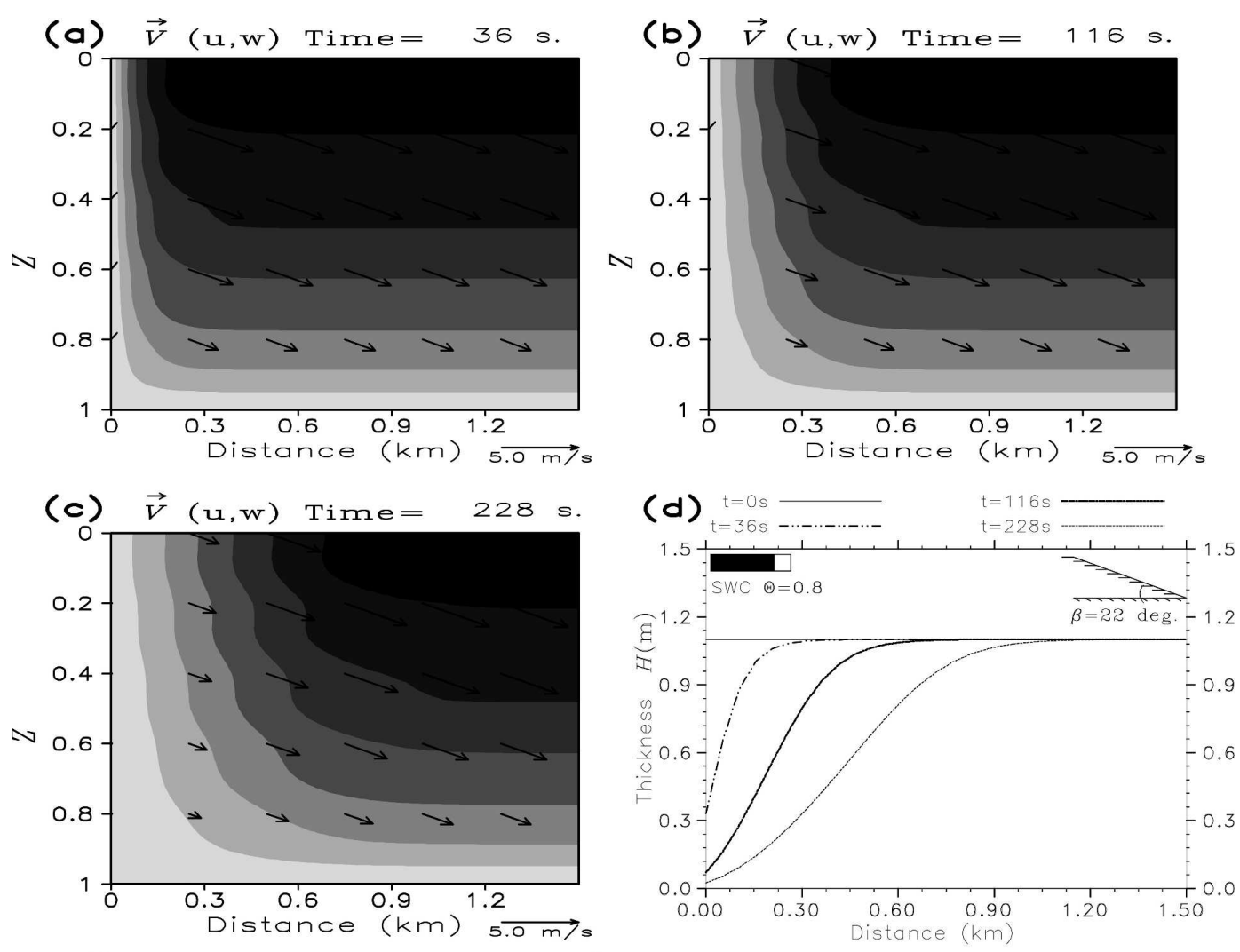

Figure 2. (a)-(c) Velocity cross sections and (d) soil thickness profiles along a vertical diagonal plane across slope top $(0,0)$ and point $(2.5 \mathrm{~km}, 2.5 \mathrm{~km})$, at three time levels: 36,116 , and $228 \mathrm{~s}$. CNTL run settings.

gradient of $R_{x z}$ and the lateral gradients of $R_{x x}$ and $R_{x y}$ to counter the driving stress $(g \partial h / \partial x)$. The horizontal gradient of the flow speed is caused by the interplay between the thinning of the upstream soil profile (affecting $g \partial h / \partial x$ ) and the ensuing advection. The nonuniform soil thickness profile produces a more complicated flow pattern and advection plays an even more important role in the horizontal mass transport. However, the general pattern of the flow is downslope and follows the bed shape in both cases. Results from more complicated soil thickness settings indicate that the differences between these two soil slab thickness profiles are typical. Force-balance models that neglect the inertial terms [the first term in Equation (2)], or models assuming nondeformed soil slab thickness profiles, generally cannot deal with dynamical flow patterns like these.

There are few observations of catastrophic mudslides, especially those occurring in remote locations. For populated regions, eyewitness accounts of duration are available, although often they are inconsistent. Quantitative measurements of velocity are rarer. An earthquake that caused a submarine turbidity current occurred in Newfoundland, Canada, in November 1929 and broke underwater cables (Bolt et al. 1975). The maximum speed of the slide was estimated from the time delays 
in the breaking of adjacent cables to be about $25 \mathrm{~m} \mathrm{~s}^{-1}$, an order of magnitude larger than for our reference case. The speed at the last cable break, however, was about $5 \mathrm{~m} \mathrm{~s}^{-1}$, close to what we found in the CNTL. Despite different moisten processes, the flow development and the ensuing steady flow are qualitatively very similar to the results presented here.

\subsection{Effects of soil depth profile and bed steepness}

We retain the reference experiment settings and conduct multiple simulations using various values of the slope angle $\beta$ and soil thickness $H_{0}$. For a slope angle of $22^{\circ}$, we tested nine different values of $H_{0}: 0.02,0.1,0.2,0.3,0.6,0.8,0.9,1.0$, and $1.1 \mathrm{~m}$. The maximum surface flow speeds that develop under the zero-stress lateral boundary conditions are $0.18,0.64,0.92,1.15,1.64,1.90,2.02,2.13$, and $2.24 \mathrm{~m} \mathrm{~s}^{-1}$, respectively. The actual values are sensitive to the ratio of $\mu_{0}$ to $\mu_{1}$, that is, the soil moisture content and the soil particle size. However, typically, the thicker the soil slab, the faster the downslope motion.

Except for the reference experiment, which has a $22^{\circ}$ slope, we set the slope steepness to be $10^{\circ}, 16^{\circ}$, and $25^{\circ}$, respectively. The first two are stable and there is no flow development. For this uniform soil depth profile, contours of $\tau_{d}$ and $\tau_{b}$ are in exact balance and are both parallel to the bed slope. The third case is stable if the soil slab is dry, as the slope value is smaller than the dry repose angle. However, because of the 0.8 relative saturation of the soil moisture, the ensuing sliding is catastrophic: the surface layer speed reaches $3.04 \mathrm{~m} \mathrm{~s}^{-1}$. The momentum associated with a $1.1-\mathrm{m}$ soil layer of $2.25-\mathrm{km}^{2}$ surface area causes a spill area of about $10 \mathrm{~km}^{2}$ before coming to rest. The bed steepness is found to be the single most significant factor in determining the flow speed. A $3^{\circ}$ difference produces a $1 \mathrm{~m} \mathrm{~s}^{-1}$ change in the achievable surface speed.

\subsection{Effects of limited range basal sliding}

We assume a bed sliding of $0.5 \mathrm{~mm} \mathrm{~s}^{-1}$, which is unidirectional (parallel to the bedding plane), and lasting for $5 \mathrm{~s}$. The basal sliding region is confined to a square. The closest and farthest corners are, respectively, 250 and $450 \mathrm{~m}$ from the crest of the slope. As expected, the differences are not large for this unstable configuration when compared with the reference run. The perturbation to the flow field also is minimal (figures not shown).

We also examined a stable configuration. It is identical to the reference case except that the soil moisture content is reduced to 0.3 relative saturation. The soil slab is deformed but finally stops. The deformation of the soil slab thickness is not confined to the basal sliding region (Figure 3), instead it follows a wave pattern both up- and downstream, with greater deformation within a short distance both up- and downstream of the perturbed region. Figure 3 is a $2 \mathrm{D}$ view of the surface velocity fields at three time levels: 4, 8, and 236 s. During sliding and shortly thereafter, surface flow speeds as large as $0.6 \mathrm{~m} \mathrm{~s}^{-1}$ occur along the diagonal. Because of the stable configuration, the flow slows and comes to a halt. The speed at $236 \mathrm{~s}$ is generally less than $0.02 \mathrm{~m} \mathrm{~s}^{-1}$, and at $300 \mathrm{~s}$ it is negligible. This conclusion does not apply to all types of basal sliding. Increasing the basal sliding speed to $5 \mathrm{~mm} \mathrm{~s}^{-1}$ liquefies the soil slab and the flow can take several minutes to 

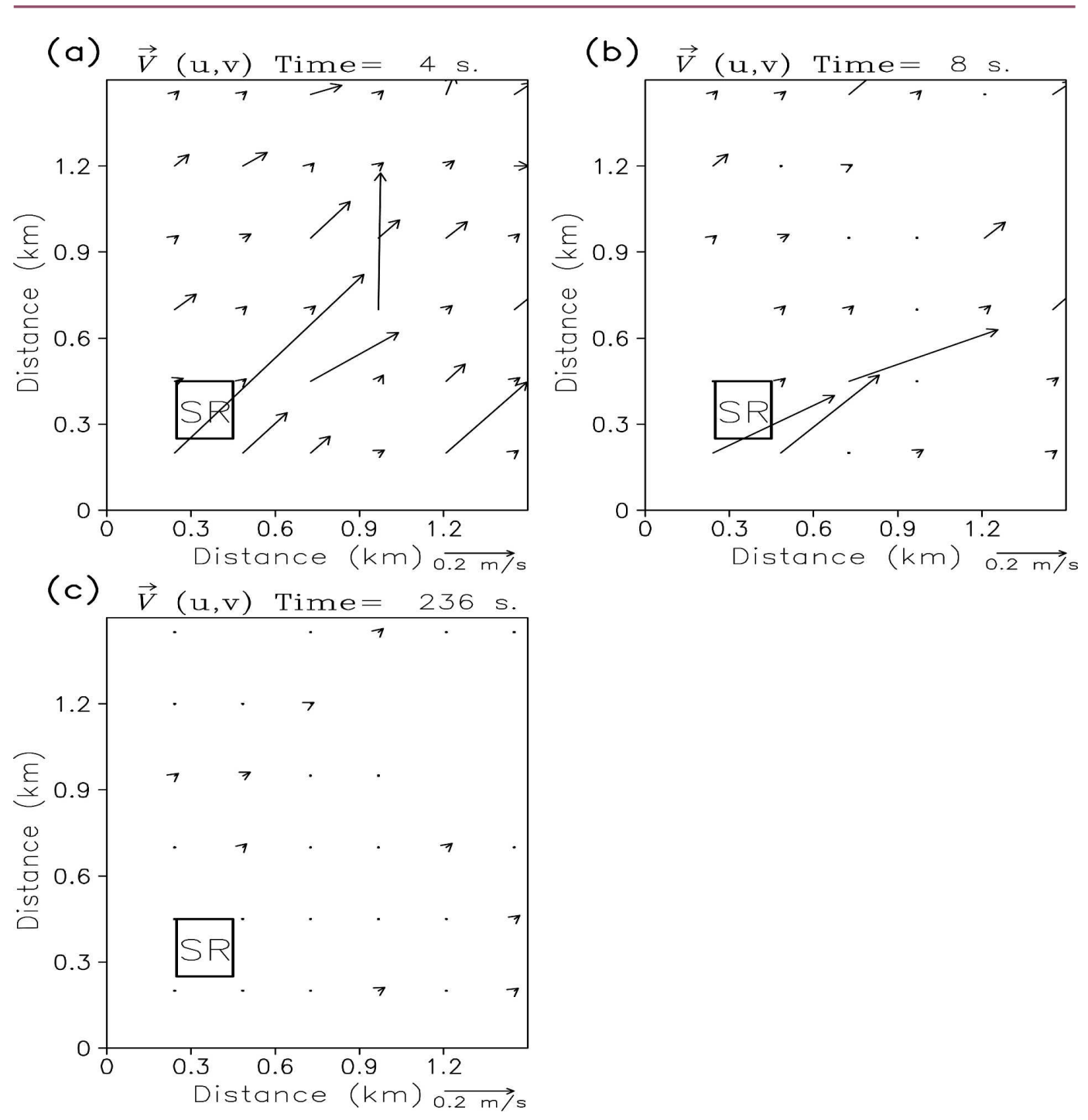

Figure 3. The effects of basal sliding: an example of stable configuration. The soil moisture content is reduced to 0.3 relative saturation. Other settings are identical to the reference run. A 2D view of the surface flow fields at three time levels: (a) 4 , (b) 8 , and (c) $236 \mathrm{~s}$. The basal sliding is assumed to be $0.5 \mathrm{~mm} \mathrm{~s}^{-1}$, unidirectional (parallel to the base plane), and lasting for $5 \mathrm{~s}$ starting from $t=0$. The basal sliding region is labeled SR in (a)-(c).

cease. Except for the magnitude, the surface velocity fields produced by this mechanism are more spatially uniform than in the CNTL run, producing a steeper edge in the soil depth profile at the top of the slope.

\subsection{Effects of soil moisture}

We examine the soil moisture effects by performing a series of reduced (2D) experiments assuming slopes of infinite width. The CNTL experiment now cor- 
responds to a unidirectional slope angle of $\sim 17^{\circ}$. As shown in Figure $4 \mathrm{a}$, before reaching a critical value of soil moisture, both the resistive and driving stresses increase linearly, due apparently to the increase of wet soil density. Upon reaching a critical soil moisture content ( $\sim 0.75$ for the CNTL), the resistive stress stalls but the loading still increases. There is an imbalance between the growth of the driving stress and the shear resistance. When the former exceeds the latter, a mudslide is initiated.

For a uniform medium, sliding commences when the driving stress $\tau_{d}$ exceeds the shear strength of the soil. Increasing soil moisture decreases stability through an increase of the soil density, and thus the loading and, more important, by making the soil less viscous and thereby decreasing the shear strength of the soil. This is applicable to all soil types.

To determine the effects of soil moisture, we maintain the slope angle but increase the soil moisture content and note the critical soil moisture value that causes a previously stable soil layer to move. We repeated the same experiments for a clay soil. For a sandy soil, as shown in Figure 4b, soil moisture is not a critical factor for a slope angle less than $15^{\circ}$, as the saturated soil slab is still stable, and the slope angle is greater than the dry repose angle. Between these two slope angles, the critical soil moisture content and the slope angle are inversely and linearly correlated. For a clay soil, we plot only the relatively higher soil moisture case, because cohesion is significant for dry clay. For the low slope angle case, clay soils generally require smaller critical soil moisture content than sandy soils, resulting primarily from the finer particle size of the clay. For example, at a slope angle of $17^{\circ}$, the critical soil moisture content for sand and clay are, respectively, 0.756 and 0.65 relative saturation. In addition, a higher soil moisture content also contributes to higher flow speeds for the unstable/sliding cases. In contrast, as discussed above, the value of $H_{0}$ is not critical for soil stability per se, but it affects the development of sliding after the flow becomes unstable.

\subsection{Effects of soil configuration}

The experiments above were all with sandy soil. The following experiments are based on a mixture of sandy and clay soils, with the sandy soil overlaying the finer-grained clay soil. We present just one case: $50 \%$ of the total depth is clay and $50 \%$ of the depth is sandy soil. This is analogous to the so-called Bootlegger Cove Formation (Bolt et al. 1975). In analyzing the stress distribution within the soil slab, we use the vertical shear stress $R_{x z}$ as an example, although the longitudinal resistive stress $\left(R_{x x}\right)$ and the lateral shear stress $R_{x y}$ behave similarly.

Compared with CNTL, which is for uniform sand (Figure 5a), the layered configuration has a pronounced stress jump at the interface (see the dot-dash lines in Figures 5a,b), which is seen in the 0.3- and 0.9-kPa isolines. The vertical shear is much larger within the bottom layer than in the top sandy layer. The surface will experience vertical plumbing as well as horizontal sliding and thus a faster reduction of mass, as shown in Figure 5c. Due apparently to the bridging effect, the upper sandy layer has a smaller vertical flow shear when compared with its uniform profile counterpart. As a consequence, the top sandy layer has a nearly uniform bulk motion. Taking the flow speed at midlevel to be the mean speed, the sand overlaying clay case achieves a maximum speed twice that of the uniform sand soil case $\left(\sim 3.2\right.$ versus $\left.\sim 1.8 \mathrm{~m} \mathrm{~s}^{-1}\right)$. 


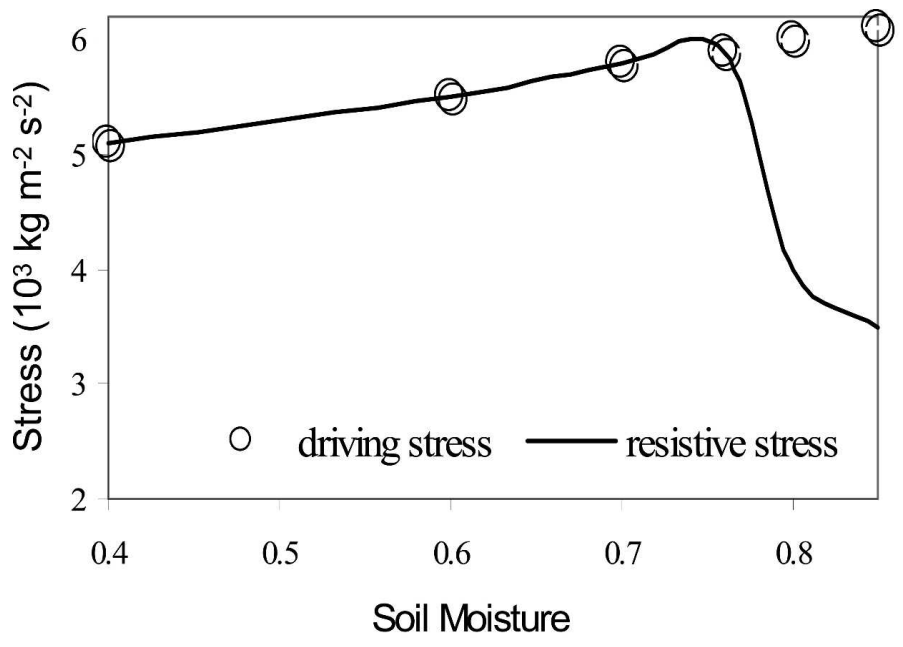

(a)

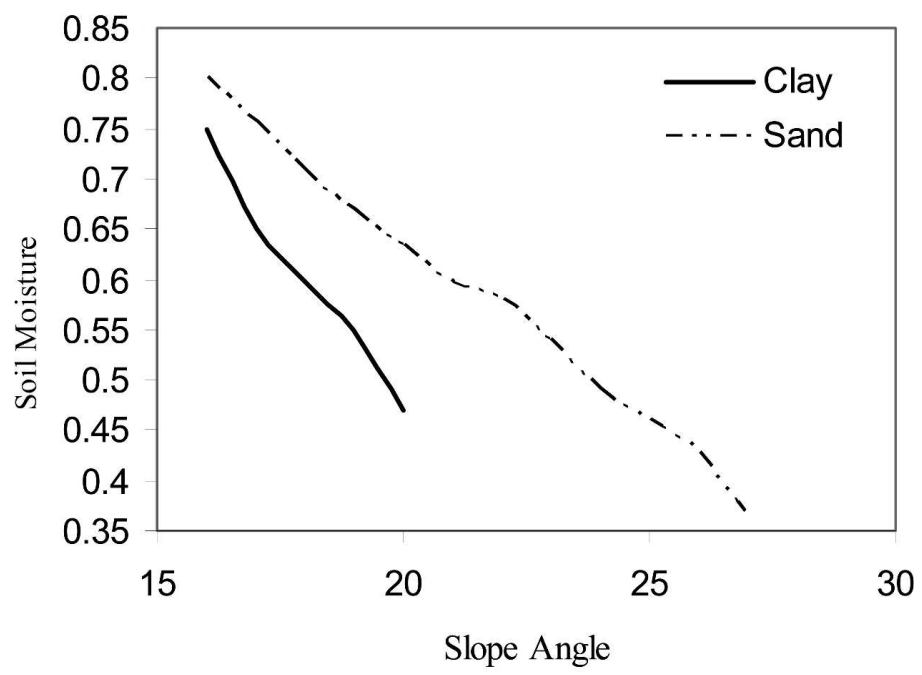

(b)

Figure 4. Effects of soil moisture: (a) Balance of the resistive and driving stresses as soil moisture increases (produced with the CNTL experiment setting of soil property while varying the soil moisture content). (b) Critical soil moisture content for different slope angles for both sandy and clay soils (produced by varying slope angles to obtain the critical soil moisture contents). Reduced 2D experiments. Parallel experiments are performed with a clay soil (as specified in Table 1). 

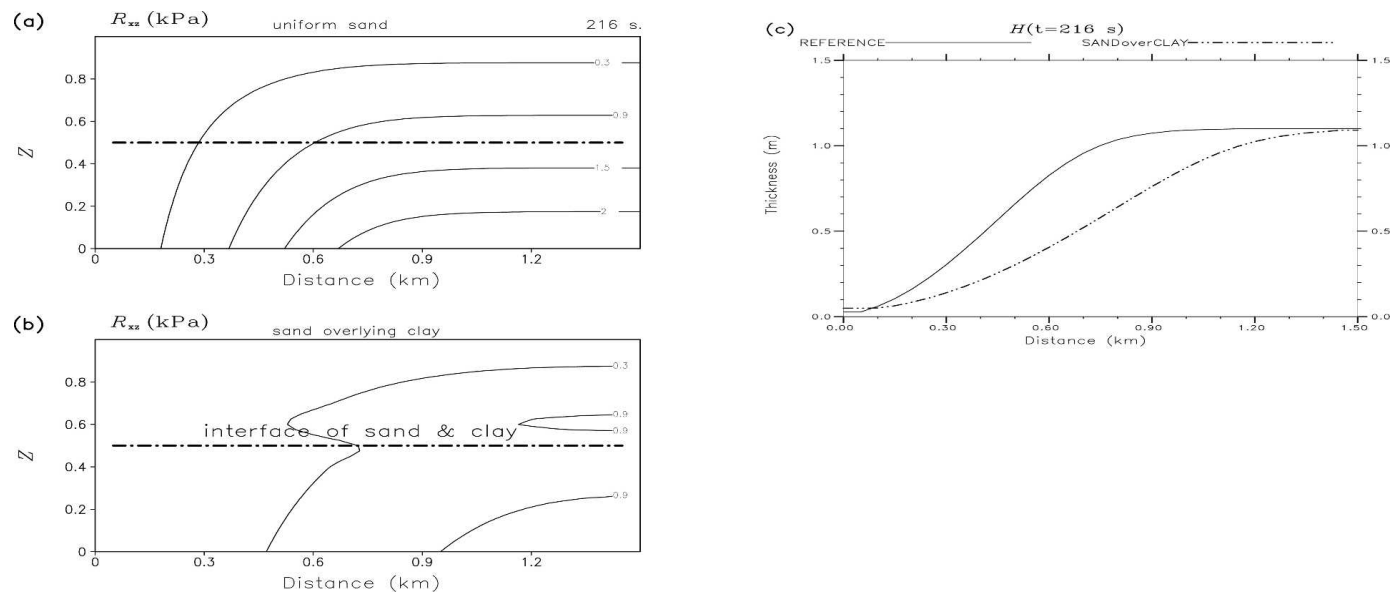

Figure 5. (a), (b) The stress $\left(R_{x z}\right)$ distribution in the soil slab from the reference run and a similar run with sand over clay, respectively. (c) The diagonal slice view of the thickness change. The dot-dash line is the initial location of the sand-clay soil interface. The stress jump is apparent at the interface separating two soils. For the sand-over-clay case, the vertical gradient of the stress is larger, resulting in a larger flow speed (surface speed of $\sim 4.2 \mathrm{~m} \mathrm{~s}^{-1}$ compared with the $2.2 \mathrm{~m} \mathrm{~s}^{-1}$ from the reference run) and quicker thinning speed.

To confirm whether the interface is the location of initial sliding for soil transitioning from dry to wet, we assumed the soils to be dry, with a 0.15 relative saturation, but otherwise the same as CNTL. We simulated the surface infiltration effects by keeping the surface at a 0.6 relative saturation and allowing the soil moistening front to propagate downward. As the moisture front reaches the interface, sliding commences. The top (sandy) layer moves like a solid body because 0.6 relative saturation is below the critical soil water content for sliding to begin, as discussed in section 4.3 (see Figure 4a).

\subsection{Effects of vegetation in halling the flow}

The previous experiments all start from zero flow. To simulate the cessation of flow, we can either gradually reduce the soil moisture content, to simulate the evapotranspiration effects, or subdivide the slope into disconnected segments, to simulate the dynamics of the root system.

Based on the reference run, we insert vegetation roots in the saturated soil slab. Root system development depends on both vegetation species and the soil in which it is growing (Eagleson 1978; Shaw 1952; Ren 2006). Here moisture extraction by plants is accounted for by assuming a distributed sink added to the 1.1-m-thick sandy soil. Specifically, once a grid point is assumed to be vegetated, the roots occupy the whole grid point and cover the entire soil depth, similar to the rectangular root profile in Ren et al. (Ren et al. 2004). Starting from the slope crest, we insert evenly isolated roots separated by $200 \mathrm{~m}$ in both the $x$ and $y$ directions.

We show the flow field in Figure 6a and the vertical stress distribution in Fig- 

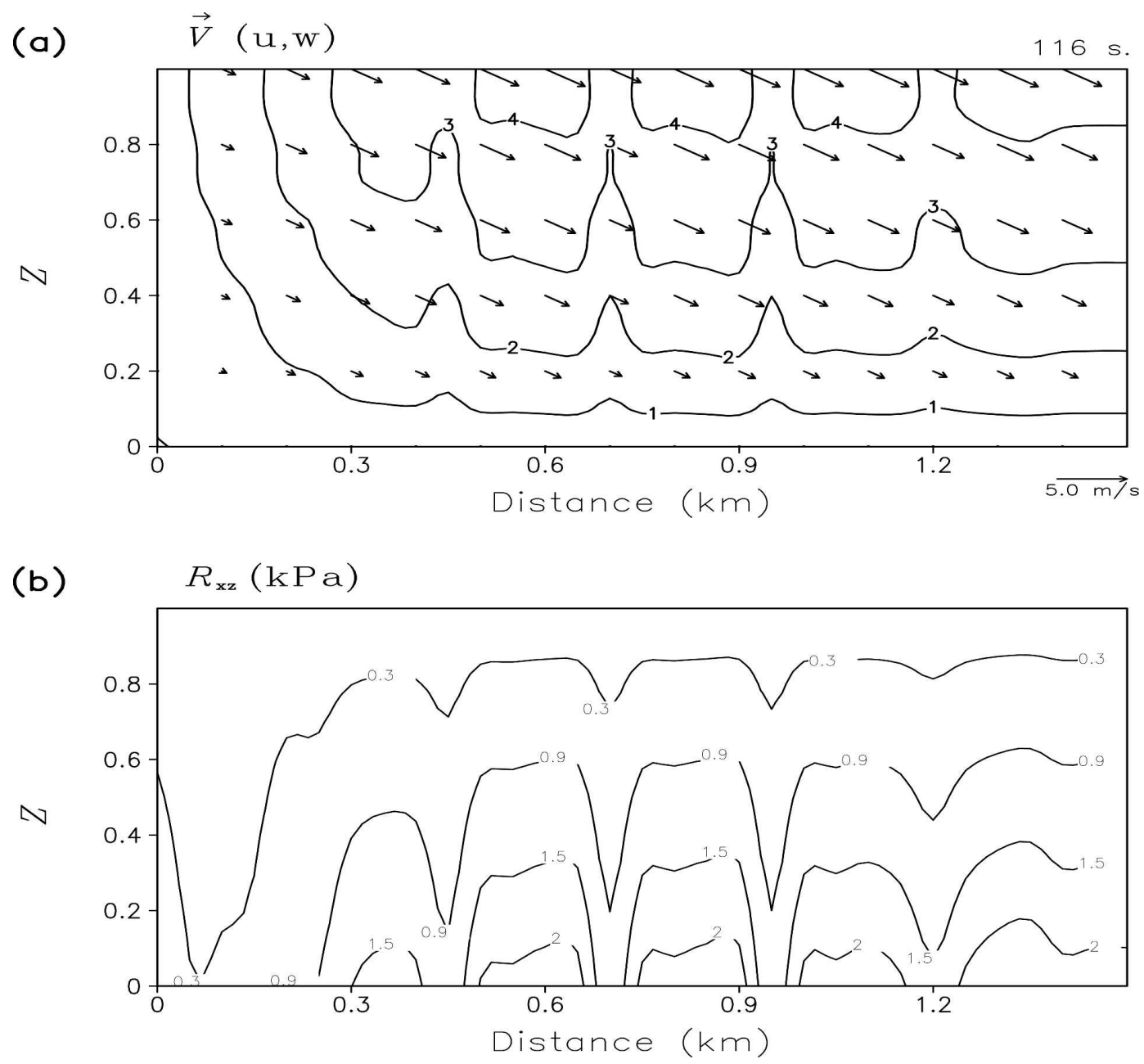

Figure 6. Dynamic drag effects of root system. (a) The flow field and (b) stress $\left(R_{x z}\right)$ distribution in the soil slab. Based on the reference run, we insert vegetation roots in the saturated soil slab. Starting from the slope crest, we insert evenly isolated roots separated by $200 \mathrm{~m}$ in both the $x$ and $y$ directions.

ure $6 \mathrm{~b}$. In Figure $6 \mathrm{a}$, there are stagnation points around the tree roots, corresponding well with the localized stress build up (the bridging effects), as indicated in Figure $6 \mathrm{~b}$. These bridging effects reduce the speeds that might have been reached by the mudslide on a free slope. Because the mud is not completely separated into isolated clumps, the general flow pattern is still apparent.

If we reduce the root depth to half that of the mud depth, that is, to $0.55 \mathrm{~m}$, the flow below the root depth has almost recovered. The locations of the roots also are advected and follow the undulations of the up- and downwelling of the soil slab. This is identified as the main reason for the reduction of the drag effects. Even so, the shear within the root zone is significantly reduced. Considering that unusually heavy rainfall is needed for the saturation of a soil slab of 1.1-m depth, the most likely scenarios for future mudslides are the less catastrophic ones initiated from 
Earth Interactions - Volume 12 (2008) - Paper No. 4 • Page 14

the very shallow layer near the surface and accumulating downstream. In that situation, the planting of deep-rooted vegetation on a slope is an effective means of preventing mudslides because the root system can significantly reduce the shear zone depth.

Aside from the obstacle effect, water pumping by trees is critical. Extended evapotranspiration may slow down, or even halt, sliding due to the drying of the soil. The transpiration of soil moisture differentiates the vegetation from the fill bulkheads usually seen at the toe of a slope to prevent landslides, because the latter merely provides a higher shear strength in the downslope region and cannot prevent the upper-stream liquefaction of the soil.

A slope angle less than $15^{\circ}$ generates a surface creeping speed less than 0.005 $\mathrm{m} \mathrm{s}^{-1}$. Although slow, the slide continues unchecked for a bare surface. However, for a uniform tree coverage during growth season in an arid climate zone, for a daylong evapotranspiration rate of $\sim 10 \mathrm{~mm} \mathrm{day}^{-1}$ (Ren and Henderson-Sellers 2006; Allen et al. 1998), the soil slab will come to a stop 3.5 days later, with the final soil slab profile being significantly modified (figures not shown).

For a given root depth, the saturated soil depth is critical for two reasons. The maximum flow speed is positively related to soil slab thickness. Thinner soil slabs allow slower flows and do not destroy the root system. Also, slow motion allows vegetation to extract soil moisture, making the soil more stable. This also holds for thinner slabs of soil resting on gentler slopes.

\section{Conclusions}

In this study we modeled a specific type of landslide, a mudslide in which the participating material is saturated or near-saturated soil. Based on a recently proposed constitutional relationship for granular flow, we constructed a new numerical model that can be used for fine-grained materials (such as clay), as well as for coarser materials (such as sand), and can be used for both arbitrary soil thickness profiles and arbitrary topography. For sufficiently steep or unstable topography, we examined the ensuing flow speeds. For stable configurations, we analyzed the stress distribution within the soil slab. We have also implemented physical parameterizations of the vegetation effects, so the model is capable of a very wide range of applications. Given the soil moisture content, vegetation distribution, and bed geometry, our model can estimate those regions most likely to become unstable. After the flow starts, we can estimate the maximum achievable velocity and the spillage area. The model can compute the distance that the slide progresses before it comes to rest. In addition, we can diagnose quantities such as the stress distributions and 3D forcing terms within the sliding media, allowing the investigation of fluid dynamical processes within the mud.

Our results can be summarized as follows:

- The magnitude of the basal sliding is an important factor for causing liquefaction of the soil slab. This approach can be extended easily to earthquake impact.

- Increased soil moisture enhances instability due primarily to the decrease in soil strength, together with the increase of loading. For a slope steepness between $15^{\circ}$ and $20^{\circ}$, clay soils generally require a smaller relative saturation to begin sliding than do sandy soils. 
Earth Interactions - Volume 12 (2008) • Paper No. 4 • Page 15

- Experiments with sand overlying clay indicate stress jumping at the interface between the two media. The interface serves as the sliding location during extended flood events, irrespective of the causes.

- The effects of vegetation include both dynamic (drag) and hydrologic (water pumping) impacts. Here, we presented preliminary results only. The role of vegetation depends on the wet soil thickness and the spacing between the trees. The thinner the saturated soil layer, the slower the flow and the vegetation has sufficient time to extract soil moisture and slow down the flow. By analyzing the effect of the vegetation root system on the stress distribution within a regime of saturated soil residing on a slope, it was found that the closer the trees the more significant the dynamical effects on the velocity field, given that roots are deeper than the shearing zone depth. This drag effect is equivalent to compacted fill bulkheads installed at the base of a landslide, to provide higher shearing strength.

The melting of frozen soil as the climate warms (Lawrence and Slater 2005), either naturally or by human activity, as a factor in increasing soil moisture, will be a future focus of study because it involves two very different rheologies: those for ice and granular materials. By varying the rheology from ice to that of saturated soil, we also studied the melting of frozen soil, which is applicable to mudslides under a warming climate. The present study found that for slopes less than $20^{\circ}$, the melting zone should be at least $20 \mathrm{~cm}$ in depth to initiate perceptible sliding.

Acknowledgments. This project was partially supported by a grant from Woodside Petroleum, Australia. The authors thank Dr. Pierre Jop for discussions on his new constitutive relationship for granular flow and Dr. van der Veen for his force-balance model and for very helpful discussions on the related issues.

\section{References}

Allen, R., L. Pereira, D. Raes, and M. Smith, 1998: Crop evapotranspiration. Guidelines for Computing Crop Water Requirements, FAO Irrigation and Drainage Paper 56 [Available online at http://www.fao.org/docrep/X0490E/x0490e0n.htm\#TopOfPage.]

Baver, L., 1940: Soil Physics. John Wiley and Sons, 370 pp.

Bolt, B., W. Horn, G. Macdonald, and R. Scott, 1975: Geological Hazards: Earthquakes, Tsunamis, Volcanoes, Avalanches, Landslides, Floods. Springer-Verlag, 328 pp.

Daerr, A., and S. Douady, 1999: Two types of avalanche behaviour in granular media. Nature, 399, 241-243.

Drucker, D. C., and W. Prager, 1952: Soil mechanics and plastic analysis or limit design. Quart. Appl. Math., 110, 157-165.

Eagleson, P. S., 1978: Climate, soil, and vegetation. 2. The distribution of annual precipitation derived from observed storm sequences. Water Resour. Res., 14, 713-721.

Frenette, R., Th. Zimmermann, and D. Eyheramendy, 2002: Unified modeling of fluid of granular flows on dam-break case. J. Hydraul. Eng., 128, 299-305.

Huang, X., and M. Garcia, 1998: A Herschel-Bulkley model for mud flow down a slope. J. Fluid Mech., 374, 305-333.

Iordanoff, I., N. Fillot, and Y. Berthier, 2005: Numerical study of a thin layer of cohesive particles under plane shearing. Powder Technol., 159, 46-54. 


\section{Earth Interactions - Volume 12 (2008) • Paper No. 4 • Page 16}

Jaeger, J. C., 1969: Elasticity, Fracture and Flow, with Engineering and Geological Applications. 3rd ed. Methuen, 268 pp.

Jop, P., Y. Forterre, and O. Pouliquen, 2006: A constitutive law for dense granular flows. Nature, 441, 727-730.

Kalaugher, P. G., R. L. P. Hodgson, and P. Grainger, 2000: Pre-failure strains as precursors of sliding in a coastal mudslide. Quart. J. Eng. Geol. Hydrogeol., 33, 325-334.

Keen, B. A., 1931: The Physical Properties of the Soil. Longmans, Green and Co., 380 pp.

Kohnke, H., 1968: Soil Physics. McGraw-Hill, 224 pp.

Lawrence, D., and A. Slater, 2005: A projection of severe near-surface permafrost degradation during the 21st century. Geophys. Res. Lett., 32, L24401, doi:10.1029/2005GL025080.

Li, J., J. Yuan, C. Bi, and D. Luo, 1983: The main features of the mudflow in Jiangjia Ravine. $Z$. Geomorph. N. F., 27, 325-341.

Mills, P., D. Loggia, and M. Tixier, 1999: Model for stationary dense granular flow along an inclined wall. Europhys. Lett., 45, 733-738.

Pouliquen, O., and Y. Forterre, 2002: Friction law for dense granular flows: Application to the motion of a mass down a rough inclined plane. J. Fluid Mech., 453, 133-151.

Qian, N., and Z. Wan, 1986: A critical review of the research on hyperconcentrated flow in China. International Research and Training Center on Erosion and Sedimentation, Beijing, 43 pp.

Ren, D., 2006: A modified Richards' equation, its adjoint, and a new perspective on land data assimilation. Meteor. Atmos. Phys., 92, 25-32.

— scaling issues for land surface modeling. Earth Interactions, 10. [Available online at http:// EarthInteractions.org.]

- M. Xue, and A. Henderson-Sellers, 2004: The effects of hydraulic lift in simulating superficial soil moisture for vegetated surfaces under dry conditions. J. Hydrometeor., 5, 1181-1191.

Roscoe, K., A. Schofield, and C. Wroth, 1958: On the yielding of soils. Geotechnique, 8, 22-53.

Shaw, B. T., Ed., 1952: Soil Physical Conditions and Plant Growth, Compiled by the Joint Committee on Soil Tilth, American Society of Agronomy, American Society of Agricultural Engineers. Academic Press, 491 pp.

Tegzes, P., T. Vicsek, and P. Schiffer, cited 2006: Avalanche dynamics in wet granular media. [Available online at http://arxiv.org/abs/cond-mat/0207731.]

Van der Veen, C., and I. Whillans, 1989: Force budget: I. Theory and numerical methods. $J$. Glaciol., 35, 53-60.

Earth Interactions is published jointly by the American Meteorological Society, the American Geophysical Union, and the Association of American Geographers. Permission to use figures, tables, and brief excerpts from this journal in scientific and educational works is hereby granted provided that the source is acknowledged. Any use of material in this journal that is determined to be "fair use" under Section 107 or that satisfies the conditions specified in Section 108 of the U.S. Copyright Law (17 USC, as revised by P.IL. 94-553) does not require the publishers' permission. For permission for any other form of copying, contact one of the copublishing societies. 


\section{University Library}

\section{- M M I N E R VA A gateway to Melbourne's research publications}

Minerva Access is the Institutional Repository of The University of Melbourne

Author/s:

Ren, Diandong;Leslie, Lance M.;KAROLY, DAVID

Title:

Landslide risk analysis using a new constitutive relationship for granular flow

Date:

2008

Citation:

Ren, D., Leslie, L. M., \& Karoly, D. (2008). Landslide risk analysis using a new constitutive relationship for granular flow. Earth Interactions, 12(4),1-16, doi: 10.1175/2007El237.1.

Publication Status:

Published

Persistent Link:

http://hdl.handle.net/11343/32759 